\title{
IgM and IgG Antibodies in Tuberculosis
}

\author{
N. Bam, R. Karn \\ Department of Internal Medicine, TU Teaching Hospital, Kathmandu, Nepal.
}

Correspondence to: Dr. Niraj Bam, Department of Internal medicine, TUTH

Email: nirajbam@ hotmail.com

\begin{abstract}
Introduction: The diagnosis of tuberculosis relies on the identification of acid-fast bacilli on unprocessed sputum smears using conventional light microscopy. Microscopy has high specificity in tuberculosis-endemic countries, but modest sensitivity which varies among laboratories (range $20 \%$ to $80 \%$ ). Moreover, the sensitivity is poor for paucibacillary disease (e.g., pediatric and HIVassociated tuberculosis). Many supportive investigations including serolological tests being utilized for tuberculosis diagnosis have wide variations in sensitivity, specificity in different studies. The aim of study was to evaluate the recombinant $38 \mathrm{KDa}$ antigen from M. tuberculosis - based Enzyme Immunoassays (EIA) test for its sensitivity, specificity and other statistical parameters.

Methods: This hospital based prospective cross-sectional study was conducted at Tribhuvan University Teaching Hospital, Kathmandu, from April 28, 2009 to November 30,2009. Sera from total 90 patients, pulmonary tuberculosis, extrapulmonary tuberculosis and non-tubercular chest infection patients who did not have past TB or exposure history, 30 in each group were used for Pathozyme Myco kit evalution to determine the $\operatorname{IgM}$ and $\operatorname{IgG}$ antibodies activity against the recombinant $38 \mathrm{KDa}$ antigen of Mycobacteria

Results: In overall tuberculosis, IgM TB had sensitivity $48.3 \%$,specificity $76.7 \%$, positive predictive value $80.6 \%$ which was statistically significant $(\mathrm{p}=0.025)$. The IgG TB had sensitivity $66.7 \%$,specificity $83.3 \%$,positive predictive value $88.9 \%$ which is statistically highly significant $(\mathrm{p}<0.001)$ to diagnose tuberculosis. Utilizing $\operatorname{IgM}$ and $\operatorname{IgG}$ both together, sensitivity decreased to $44.3 \%$, but specificity increased to $90.0 \%$ and positive predictive value $88.5 \%$, which was statistically significant $(\mathrm{p}=0.006)$ for the diagnosis of tuberculosis.
\end{abstract}

Conclusions: IgG TB antibody has high sensitivity and specificity for tuberculosis diagnosis, but IgM antibody should also be evaluated along with IgG antibody to increase specificity.

Keywords: Extrapulmonary tuberculosis (EPTB), 38 kDa antigen, IgM, IgG TB antibody, PathozymeMyco, Pulmonary tuberculosis (PTB).

\section{Introduction}

The global tuberculosis epidemic results in nearly 2 million deaths and 10 million new cases of the disease a year. The vast majority of tuberculosis patients live in developing countries, where the diagnosis of tuberculosis relies on the identification of acid-fast bacilli on unprocessed sputum smears using conventional light microscopy. Microscopy has high specificity in tuberculosis-endemic countries, but modest sensitivity, which varies, among laboratories (range $20 \%$ to $80 \%){ }^{1}$ Moreover, the sensitivity is poor for paucibacillary disease (e.g., pediatric and HIV-associated 
$\lg M$ and IgG Antibodies in Tuberculosis

tuberculosis). ${ }^{2}$ Fundamental to any attack on tuberculosis problem, is the ability to recognize this disease using diagnostic methods that are at low cost and readily applied to number of persons under condition that exists in area of high tuberculosis prevalence. The diagnosis of tuberculosis in its early stage is difficult. Many times the clinical features of the disease are not specific in endemic zones like our country Nepal. At the same time, sputum microscopy cannot be applied in children because they rarely produce sputum. Sputum culture is time consuming. ${ }^{\mathbf{3}, \mathbf{4}}$ Although active tubercular cavities are seen in chest X-Ray and the patient has the disease clinically, negative AFB sputum smears are often obtained. ${ }^{5}$

Although often on the basis of suspicion, X-ray findings have been estimated as atypical in more than $30 \%$ of patients with Tuberculosis in developed countries. ${ }^{6}$ In adults the Tuberculin skin test cannot discriminate between active disease and previous exposure to mycobacterium tuberculosis. ${ }^{6}$ There is also wide variation in sensitivity, specificity of different tools developed for diagnosing extrapulmonary tuberculosis in different clinical studies. If other evidences strongly suggest tuberculosis, despite negative sputum smear, chemotherapy is often initiated before the results of sputum culture are known. This approach may avoid a delay of 6 to 8 weeks before the administration of specific treatment but the risk of committing an error still remains. Many times, all the clinical pictures are supporting tuberculosis, but the documented evidences remain lacking to start the chemotherapy. Thus, the development of rapid and accurate new diagnostic tools is imperative. Keeping the magnitude of tuberculosis in consideration, a technique is highly required which can perform multiple rapid assays at reasonable cost with good amount of specificity in a routine hospital set up and even at peripheral centres. There is a promise in serodiagnostic tests such as Enzyme-Linked Immuno Sorbent Assay (ELISA), which are of value in early diagnosis of the disease because of their easy performance. ${ }^{7}$ These are among the rapid, reliable and less costly diagnostic methods for the detection of tuberculosis. ${ }^{8}$ The goal of present study was, to determine the sensitivity, specificity and other statistical parameters of serological tests compared to traditional methods.

During the active phase of tuberculosis, antibodies especially $\operatorname{IgM}$ and $\mathrm{IgG}$ are developed against different mycobacterial antigens and these can be detected in patients' sera within a month after the development of the disease. ${ }^{9}$ PATHOZYME-MYCO are Enzyme-immunoassays (EIA) for the detection of antibodies to mycobacterium species in human serum. Individual assays are available for IgM and IgG TB antibodies. These tests utilize two highly purified antigens to ensure good sensitivity and specificity. The first antigen purified from Mycobacterium tuberculosis, is highly antigenic and present in all the members of the genus Mycobacterium. 10-12 The second antigen utilized in this assay is a highly specific recombinant $38 \mathrm{KDa}$ antigen from $M$. tuberculosis which has been expressed and purified from Escherichia coli. ${ }^{13}$ This antigen has been reported as the single most important antigen for the serodiagnosis of Tuberculosis. ${ }^{14}$ It is a unique disease associated protein ${ }^{15}$, which appears to be completely specific to the Mycobacterium tuberculosis. ${ }^{16,17}$ From the limited studies, BCG vaccination has not been shown to elevate antibody levels. ${ }^{18}$

\section{Methods}

This is a hospital based cross-sectional prospective study conducted at Tribhuvan University Teaching Hospital, Kathmandu, Nepal from April 28, 2009 to November 30, 2009. This study comprised of 90 patients of which 30 were sputum positive Tuberculosis(PTB), 30 were Extrapulmonary tuberculosis (EPTB) and 30 subjects were taken as control who had chest infections other than tuberculosis. EPTB group consisted of 25 tubercular pleural effusions and 5 cases of tubercular lymphadenitis.

Sera from all 90 patients were collected, who were indoor patients, admitted in the Department of medicine of Teaching hospital, Kathmandu. None of the either sputum positive tuberculosis (PTB) or extrapulmonary tuberculosis (EPTB) group were on antitubercular treatment(ATT) at the time of blood collection. A detailed history was taken with particular emphasis on cough, fever, chest pain, haemoptysis, loss of weight, appetite along with a palpable lymphnode and findings on chest xray. The relevant data pertaining to personal, past, family, socioeconomic history and history of past tuberculosis were recorded.

Sera from 30 control subjects were taken, control included patients with chest infection other than tuberculosis who were diagnosed on the basis of clinical and radiological findings with no past or family history of tuberculosis.

Patients of less than 16 years of age and those already under antitubercular regimen were excluded. Also those unwilling to give the consent for the study and unable to undergo basic investigations needed for the study protocol were also excluded from the study.

Routine haematological and biochemical investigations were sent along with various specific tests (Table 1). 
Table1: Investigations done material is again washed away. On addition of the substrate, stabilized 3,3,5,5 Tetra- methyl benzidine (TMB), a colour will develop only in those wells in which the enzyme is present, indicating the presence of human antiMycobacterium species antibody.The enzyme reaction is stopped by the addition of dilute sulphuric acid and the absorbance is then measured at $450 \mathrm{~nm}$.For the IgM assay any result with an optical density(OD) greater than the cut off level is considered positive. For IgG test,a standard curve may be constructed by plotting the optical densities of the references(Positive result: greater than $900 \mathrm{U} / \mathrm{ml}$ ).The units $/ \mathrm{ml}$ of the unknown sera are then determined from the standard curve.

Data was analyzed by Statistical package for the Social Sciences (SPSS v 16). When a variable had "Yes" or "No" categories, the "No" response was used as the reference group. All the tests of significance were two-tailed and a p-value less than 0.05 were considered to be significant. Odd's ratio(OR) and 95\% Confidence interval (CI) were estimated using cross tabulation method(Chi square $\mathrm{t}$ test).

\section{Results}

Out of the total 90 patients in our study, 62(68.89\%) were males and 28(31.11\%) were females (Fig. 1). Each of the pulmonary tuberculosis(PTB), extrapulmonary tuberculosis (EPTB) and non tubercular chest infection(NTB) group, had $30(33.33 \%)$ patients. The ratio of male:female was 3:1(45:15) in tubercular patients. All the patients were between 16 to 78 years of age, The mean age was 44.88 in tubercular patients and 48.20 in control subjects.

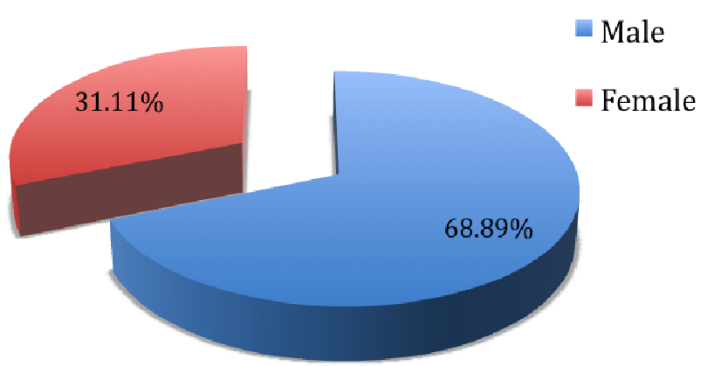

Fig. 1: Gender distribution of the patients.

In general, IgM antibodies alone were present in $36, \operatorname{IgG}$ $\mathrm{TB}$ in $45, \operatorname{IgM}$ and $\operatorname{IgG} \mathrm{TB}$ both present in 26 of the patients (Table 2). 
IgM and IgG Antibodies in Tuberculosis

Table.2 Frequencies of different antibodies

$\begin{array}{llll}\text { Antibodies } & \text { IgM TB } & \text { IgG TB } & \text { IgM TB+IgG TB } \\ \text { Positive } & 36(40 \%) & 45(50 \%) & 26(28.9 \%) \\ \text { Negative } & 54(60 \%) & 45(50 \%) & 64(71.1 \%)\end{array}$

In 30 patients of PTB group, IgM TB had 50\% sensitivity, $76.7 \%$ specificity and $68.2 \%$ positive predictive value (Table 3). IgG TB had $70 \%$ sensitivity, $83.3 \%$ specificity and $80 \%$ positive predictive value and it was statistically highly significant for PTB diagnosis ( $\mathrm{p}$ value $<0.001$ ). While utilizing both $\operatorname{IgM}$ and $\operatorname{IgG} \mathrm{TB}, 43.3 \%$ sensitivity, $90.0 \%$ specificity and positive predictive value was $81.3 \%$ for diagnosing PTB, also they were significant for PTB diagnosis ( $\mathrm{p}$ value 0.0370 ).
The IgG TB had sensitivity $66.7 \%$, specificity $83.3 \%$, positive predictive value $88.9 \%$ which is statistically highly significant $(\mathrm{p}<0.001)$ on tuberculosis diagnosis. Utilizing $\operatorname{IgM}$ and $\operatorname{IgG}$ both together, sensitivity decreased to $44.3 \%$,but the specificity increased to $90.0 \%$ and positive predictive value of $88.5 \%$, which was statistically significant $(\mathrm{p}=0.006)$ for tuberculosis diagnosis.

\section{Discussion}

We analyzed sera obtained from 90 patients, 30 each from Pulmonary tuberculosis (PTB), Extrapulmonary tuberculosis(EPTB) and non tubercular chest infections, who did not have any history of contact or past TB. The male: female ratio was $3: 1(45: 15)$ in tubercular patients. There

Table 3: Significance of different antibodies for diagnosing PTB

\begin{tabular}{llllll} 
Antibodies & Sensitivity & Specificity & $\begin{array}{l}\text { Positive } \\
\text { predictive Value }\end{array}$ & Odd's ratio(95\% CI) & P value \\
\hline IgMTB & $50.0 \%$ & $76.7 \%$ & $68.2 \%$ & $2.143(1.022-4.495)$ & 0.060 \\
IgGTB & $70.0 \%$ & $83.3 \%$ & $80.0 \%$ & $4.200(1.825-9.668)$ & $<0.001$ \\
IgM+IgGTB & $48.3 \%$ & $90.0 \%$ & $81.3 \%$ & $4.333(1.374-13.670)$ & 0.037
\end{tabular}

The sensitivity, specificity and positive predictive value for diagnosing EPTB, was $46.7 \%, 76.7 \%$ and $66.7 \%$ consecutively for IgM TB, $63.3 \%, 83.3 \%$ and $79.2 \%$ for $\operatorname{IgG}$ $\mathrm{TB}, 33.3 \%, 90 \%$ and $86.9 \%$ consecutively for combined $\operatorname{IgM}$ and $\operatorname{IgGTB}$ (Table 4). Both $\operatorname{IgM}+\operatorname{IgM}$ TB were significant for EPTB (p value 0.040 ), IgG TB was statistically highly significant ( $\mathrm{p}$ value $<0.001$ ) but IgM TB was less significant for EPTB ( $p$ value 0.103 ). were more males with tuberculosis in the elder age groups due to waning immunity and different co-morbidities. ${ }^{19}$ Based on the results, a wide range of antibody levels was observed in our study patients. The IgM TB antibody was present in 36(40\%), IgG antibody in 45(50\%) and both IgM, $\mathrm{IgG}$ antibodies were present in 26 (28.9\%) of total patients.

In smear positive Pulmonary tuberculosis(PTB) group, IgG TB antibody had high sensitivity (70\%), high

Table 4: Significance of different antibodies for diagnosing EPTB

\begin{tabular}{llllll} 
Antibodies & Sensitivity & Specificity & $\begin{array}{l}\text { Positive } \\
\text { predictive value }\end{array}$ & Odd's ratio(95\% CI) & P value \\
\hline IgM TB & $46.7 \%$ & $76.7 \%$ & $66.7 \%$ & $2.00(0.942-4.247)$ & 0.103 \\
IgG TB & $63.3 \%$ & $83.3 \%$ & $79.2 \%$ & $3.800(3.800-8.848)$ & $<0.001$ \\
IgM+IgG TB & $38.3 \%$ & $90.0 \%$ & $86.9 \%$ & $4.333(1.017-9.922)$ & 0.040
\end{tabular}

Overall, the IgM TB had sensitivity $48.3 \%$, specificity $76.7 \%$, positive predictive value $80.6 \%$, which was significant $(\mathrm{p}=0.025)$ for dignosing tuberculosis (Table 5). specificity $(83.3 \%)$ and positive predictive value $(80.0 \%)$, which is statistically highly significant $(\mathrm{p}<$ 0.001).Though IgM antibody had good sensitivity $50 \%$,

Table 5: Significance of different antibodies for diagnosing all TB cases

\begin{tabular}{llllll} 
Antibodies & Sensitivity & Specificity & $\begin{array}{l}\text { Positive } \\
\text { predictive value }\end{array}$ & Odd's ratio(95\% CI) & Pvalue \\
\hline IgMTB & $48.3 \%$ & $76.7 \%$ & $80.6 \%$ & $2.07(1.03-4.17)$ & 0.035 \\
IgGTB & $66.7 \%$ & $83.3 \%$ & $88.9 \%$ & $4.00(1.76-9.08)$ & $<0.001$ \\
IgMTB+IgGTB & $44.3 \%$ & $90.0 \%$ & $88.5 \%$ & $3.83(1.25-11.75)$ & 0.006
\end{tabular}


good specificity $76.7 \%$ with positive predictive value $68.20 \%$, was not statically significant. Combined IgM and IgG TB had sensitivity $48.3 \%$, but high specificity $90 \%$, positive predictive value of $81.3 \%$, was statistically significant in PTB group.

In Extrapulmonary tuberculosis (EPTB) group, IgG TB antibody had sensitivity of $63.3 \%$, specificity of $83.30 \%$ and positive predictive value of $79.2 \%$, which was also statistically highly significant $(\mathrm{p}<0.001)$. IgM antibody had sensitivity $46.7 \%$, specificity $76.7 \%$, and positive predictive value $66.7 \%$ which was not significant in EPTB. Combined IgM and IgG TB antibody had low sensitivity (38.3\%) but high specificity $(90.0 \%)$ and a positive predictive value of $86.9 \%$ which was statistically significant $(\mathrm{p}=0.040)$.

In overall Tuberculosis cases, PTB and EPTB, IgG TB antibody had good sensitivity $66.7 \%$, high specificity $83.3 \%$ and positive predictive value $88.9 \%$ which was statistically significant( $\mathrm{p}<0.001)$. IgM TB antibody had sensitivity $48.3 \%$, specificity $76.7 \%$, positive predictive value $80.6 \%$ which was also statistically significant ( $\mathrm{p}$ value 0.035). Combined IgM and IgG antibody had overall sensitivity $44.3 \%$, high specificity $90.0 \%$, positive predictive value $88.5 \%$ which was also significant( $\mathrm{p}$ value 0.006). Measurement of $\mathrm{IgG}$ alone cannot differentiate patients with active disease from those who had TB in the preceding few years. ${ }^{5}$ However, the IgG level is valuable in differentiating Tuberculosis patients from those with non tubercular and no prior history of TB. ${ }^{5}$ Few other studies have shown a relationship between $\mathrm{IgG}$ levels and the previous TB disease. ${ }^{20,21}$ Patients showed slight raised IgM, who had no history of TB in the past. The level of IgM was not statistically significant in majority of TB patients who had a history of TB in the last few years. ${ }^{21}$ Based on this study results, it may be concluded that variation in IgM \& $\mathrm{IgG}$ antibody levels could be an important index in determining the stage of tuberculosis, so raised $\mathrm{IgG} \&$ low level of $\operatorname{IgM}$, could represent as a feature in evaluation of secondary disease. ${ }^{5}$

We found a significant correlation between antibody levels and smear positivity. The highest levels of $\mathrm{IgG}$ antibody were encountered in AFB smear positive patients (PTB) and the lower in patients with a negative smear and EPTB in this study. Turneer and colleagues previously pointed out similar results. ${ }^{22}$ Sero-diagnosis of tuberculosis using various antigens-based ELISA tests has been reviewed by Bhatia et al. ${ }^{23}$ The review mentioned IgG antibody test to be more sensitive and specific than IgM antibody. Uma et al. reported sensitivity as $61 \%$ for IgG and only $10 \%$ for IgM antibody using $38 \mathrm{kDa}$ antigen. ${ }^{24}$ Mathai et al. compared five different antigens-based commercial kits and the sensitivity varied from 46 to $68 \% .^{25}$

The threshold values of $200 \mathrm{U}$ and $250 \mathrm{U}$ have been used in other studies. ${ }^{26,27}$ In our present study, threshold had to be raised to $900 \mathrm{U}$. Therefore, setting up of threshold values for the individual laboratory based on the local population is required for adequate sensitivity and specificity. ${ }^{28}$

The duration of illness and the age group also need to be considered for the negative antibody tests. ${ }^{28}$ lower positivity has been reported for age group 1-14 years and duration of less than 3 months in case of tuberculous lymphadenitis. ${ }^{29}$ The class of the antibody is also an important factor. Immuno- globulin $\mathrm{G}$ holds the great promise in diagnosis of active tuberculosis both in children and in adults. ${ }^{23}$ Sensitivity and specificity for IgG antibody was found to be in the range of 75-100\% in various other Indian reports. 23,26,27,28,29,30,31 However, proper evaluation, setting up of thresholds, and reproducibility study was lacking in most of the studies. ${ }^{28}$

The IgM antibody is the first to appear for any antigen and therefore could be expected to be of diagnostic value for the recent tuberculosis. ${ }^{28}$ However, in case of $\operatorname{IgM}$ antibodies test, the sensitivity was low $(48.3 \%)$ in our study. This possibly could be due to inclusion of PTB cases with a symptomatic history of 1-12 months. As a result of longer duration of infection, the $\operatorname{IgM}$ antibodies might have declined in the proportion of PTB cases. Longer incubation period in case of tuberculosis may result in decline of $\operatorname{IgM}$ before symptoms appear. However, the IgM antibody appears to be less sensitive as evident in the present study and also has been reported by others. ${ }^{23,27,32}$ Bhatia et al reported $\operatorname{IgG}$ sensitivity of $94 \%$ and $\operatorname{IgM}$ sensitivity of only $33 \%$ in extra-PTB, whereas Maheshwari et al observed IgG sensitivity of $75 \%$ and $\operatorname{IgM}$ sensitivity of $37.5 \%$ in tuberculoma cases. ${ }^{23,27}$ In a metaanalysis, the results for all commercial kits for serological diagnosis of tuberculosis, varied markedly with sensitivity ranging from $15.7 \%$ to $89.2 \%$ and specificity ranging from $50 \%$ to $100 \% .{ }^{33}$ In general, higher sensitivity comes at the cost of lower specificity. One of the major problems in the serodiagnosis of TB has been heterologous antibody responses to various $M$. tuberculosis antigens. ${ }^{33}$ Hence, the multicentric trials on the diagnostic utility of the test on large number of cases of tuberculosis are suggested.

\section{Conclusions}

IgM TB antibody had sensitivity $48.3 \%$, specificity $76.7 \%$, and positive predictive value $80.6 \%$ which was statistically significant. IgG TB antibody had good sensitivity $66.7 \%$, high specificity $83.3 \%$, positive predictive value 
$88.9 \%$ which was statistically very significant. On utilizing both IgM and IgG TB antibodies, sensitivity decreased to $44.3 \%$ but very high specificity $90.0 \%$, positive predictive value $88.5 \%$ which was also statistically significant. So this study recommends evaluating both the $\operatorname{IgM}$ and $\mathrm{IgG}$ antibodies to increase the specificity.

\section{Acknowledgements}

Our heartful thanks go to Mr.Sudeep Adhikari and friends, Microbiology lab technicians, TUTH for their constant help during serum TB antibodies analysis. We acknowledge the MD, Internal Medicine residents who have supported us during the data collection of the cases.

\section{References}

1. WHO Tuberculosis. Fact Sheet No. 104 (World Health Organization, Geneva) Revised 2002.

2. Steingart KR, Henry $M$ et al. A systematic review: Commercial serological antibody tests for the diagnosis of Pulmonary tuberculosis; PLoS Med.2007 Jun; 4(6): e202.

3. Boyd JC, Marr JJ et al. Decreasing reliability of Acidfast smear techniques for detection of tuberculosis. Ann. Intern. Medicine 1975;82:489-492

4. Kim TC, Blackman RS, Heatwole KM et al. Acid-fast bacilli in sputum smears of patients with pulmonary tuberculosis, prevalence and significance of negative smears pretreatment and positive smears posttreatment. Am Rev Respir Dis. 1984; 129(2): 264-268

5. Azar D. Khosravi, Roya Torabizadeh and Abdulamir Landi. Investigation of the level of $\operatorname{IgG}, \operatorname{IgM}$ and $\operatorname{IgA}$ antibodies against $\mathrm{A} 60$ antigen in tuberculosis patients referred to PHLS, Ahvaz, Iran. Pakistan Journal of Meical sciences,2005,vol.21,(4) 465-469

6. Glassroth J, Robins AG, Snider DE. Tuberculosis in the 1980s. New England J Med.1980;26;302(26)14411450 .

7. Raja A, Uma Devi KR, Ramalingam B et al. Immunoglobulin $\mathrm{G}, \mathrm{A}$, and $\mathrm{M}$ responses in serum and circulating immune complexes elicited by the 16kilodalton antigen of Mycobacterium tuberculosis. J Clin Microbiol 2002; 9: 308-12

8. Maekura R, Okuda Y, and Nakagawa M. Clinical evaluation of anti-tuberculous glycolipid immunoglobulin G antibody assay for rapid serodiagnosis of pulmonary tuberculosis. J Clin
Microbiol 2001; 39: 3603-8.

9. Chiang IH, Suo J, and Bai KJ. Serodiagnosis of tuberculosis. A study comparing three specific mycobacterial antigens. Am J Respir Crit Care Med 1997; 156: 906-11.

10. Hunter S.W.,Gaylord H. and Brennan P.J. Structure and antigenicity of the phosphorylated lipopoplysaccharide antigens from the leprosy and tubercle bacilli. J. Biol. Chem.261(26): 12345-1235

11. Hunter S.W. and Brennan P.J. (1990). Evidence for the presence of a phosphatidylinositol anchor on the lipoarabinomannan and lipomannan of Mycobacterium tuberculosis. J. Biol. Chem.265 (16): 9272-9279

12. Sad E, Brennan P.J., Herrera T. et al. Evaluation of lipoarabinomannan for the serological diagnosis of tuberculosis. J Clin. Microbiol.28(12): 2587-2590

13. Singh M, Andersen A.B, Mc Carthy et al. The Mycobacterium tuberculosis 38-KDa antigen: Overproduction in Escherichia coli,purification and characterization. Gene.1992, 117:53-60

14. Jackett PS, Bothamley GH, Batra HV et al. Specificity of antibodies to immunodominant mycobacterial antigens in pulmonary tuberculosis. J clin. Microbiol.1988,26(11):2313-2318.

15. Espitia C, Cervera I, Gonzalez R et al. A $38 \mathrm{KDa}$ Mycobacterium tuberculosis antigen associated with infection, its isolation and serological evaluation. J.Exp.Immunol.1989(77):373-377

16. Ivanji J, Bothamley $\mathrm{GH}$ and Jackett PS, Immunodiagnostic assays for tuberculosis and Leprosy. Brit. Med. Bull.1988,44(3):635-649

17. Ivanyl J, Serological tests for the diagnosis of tuberculosis and Leprosy.Proceedings from the Sixth International Cons on Rapid methods and Automation in Microbiology and Immunology. 1990

18. Krambovitis E, Detection of antibodies to Mycobacterium tuberculosis plasma membrane antigen by Enzyme Linked immunosorbent assays. J. Med. Microbiol. 1986.21:257-264

19. Mario C. Raviglione, Richard J. O' Brien, Tuberculosis: Harrison's Principles of Internal Medicine, 16 th Edition,2005, vol.1, chapter 150; 953-966

20. Kaplan MH, and Chase MW. Antibodies to mycobacterium in human tuberculosis. Development of antibodies before and after antimicrobial therapy. 
$\mathrm{J}$ Infect Dis 1980; 142:825-34.

21. Charpin O, Herbault H, and Gevaduan J. Value of ELISA using A60 antigen in the diagnosis of active pulmonary tuberculosis. Am Rev Respir Dis 1990; 142:380-4.

22. Turneer M, Van Vooren JP, and Bruyn JD. Humoral immune response in human tuberculosis; immunoglobulins $\mathrm{G}, \mathrm{A}$ and $\mathrm{M}$ directed against the purified P32 antigen of Mycobacterium bovis, Bacilli Calmette-Guerin. J Clin Microbiol 1988; 26:1714-9.

23. Bhatia AS, Kumar S, Harinath BC. Immune-Diagnosis of Tuberculosis: An update. Indian J Clin Biochem 2003;18:1-5.

24. Uma Devi K R, Ramalingam B, Brennan PJ et al. Specific and early detection of $\operatorname{IgG}, \operatorname{Ig} \mathrm{A}$ and $\operatorname{IgM}$ antibodies to Mycobacterium tuberculosis $38 \mathrm{kDa}$ antigen in pulmonary tuberculosis. Tuberculosis 2001;81:249-53.

25. Mathai E, Rajkumari R, Kuruvilla P J et al. Evaluation of serological test for the diagnosis of tuberculosis. Indian J Pathol Microbiol 2002;45:303-5.

26. Munshi MM, Chiddarwar S, Patel Aet al. Serodiagnosis of Extra-pulmonary tuberculosis by ELISA. Indian J Pathol Microbiol 1993;36:356-60.

27. Maheshwari A, Gupta HL, Gupta S et al. Diagnostic utility of estimation of mycobacterial Antigen A60 specific immunoglobulins in serum and CSF in adult neurotuberculosis. J Commun Dis 2000;32:54-60.

28. Kalantri Y, Hemvani N, Bhatia GC et al. Elisa kit evaluation for IGG and IGM antibodies to A60 tubercular protein. Indian Journal of Medical sciences 2005,vol. 59,8:337-346

29. Ahmed Z, Pandey DK and Beg M. Role of Anti-A60 IgG titers were measured in 120 FNAC confirmed patients of tuberculous lymphadenitis. Indian J Tuber 2002;49:101.

30. Meena LS, Goel S, Sharma SK et al. Comparative study of three different polysaccharide antigens for the serodiagnosis of tuberculosis. J Clin Lab Anal 2002;16:151-5.

31. Anuradha S, Kaur R, Singh NP et al. Serodiagnosis of extra pulmonary tuberculosis using A-60 antigen. $\mathrm{J}$ Commun Dis 2001;33:12-6.

32. Gupta S, Kumari S, Banwalikar JN et al. Diagnostic utility of the estimation of mycobacterial Antigen A60 specific immunoglobulins $\operatorname{IgM}, \operatorname{Ig} \mathrm{A}$ and $\operatorname{IgG}$ in the sera of cases of adult human tuberculosis. Tuber Lung Dis 1995;76:418-24.

33. Sang-Nae Cho. Current Issues on Molecular and Immunological diagnosis of tuberculosis. Yonsei Med J. 2007; 48(3):347-359. 